\section{Eye drops}

Editor, -The excellent article by Michael Steiner (Aust Prescr 2008;31:16-17) prompts me to submit an alternative method demonstrated by an ophthalmologist many years ago. It is particularly useful when drops are to be administered to children and elderly people.

It involves approaching the eye from across the nose into the corner near the nose so that the dropper is unseen and the tendency to blink is reduced. Even with the eye closed the drops eventually enter the area around the eye as shown by a study with pilocarpine at the time.

- Tilt the head back or lie down to face the ceiling.

- Approach the eye from across the nose and hold the dropper above the inner corner without touching it.

- Squeeze out a drop and feel the liquid run into the eye.

- Gentle pressure on the bridge of the nose for 1 to 2 minutes will slow draining and increase effect. Rubbing the eye decreases it.
The eye may be closed while instilling the drops, especially for children, as drops flow into the eye on opening.

- Leave 5 minutes between

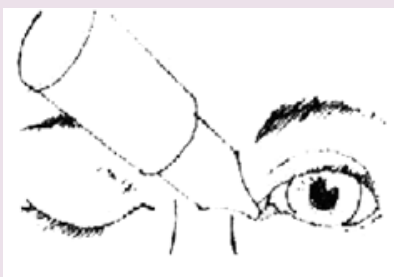
different drops.

Peter Bayly

Consultant pharmacist

Burnside, SA

Dr Steiner, author of the article, comments:

There are of course many ways that eye drops can be instilled and that described by Peter Bayly is especially useful in fractious, frightened children. The only minor problem with it is the small risk of washing skin flora into the conjunctival sac. However, it is useful when more traditional techniques are not possible.

\title{
Subsidised medicines for Aboriginal and Torres Strait Islander people
}

Since August 2006, the Pharmaceutical Benefits Scheme (PBS) has been including new listings specifically for the treatment of common conditions in Aboriginal and Torres Strait Islander people. Some listings are medicines new to the PBS, while others vary the restrictions for prescribing existing PBS items. For the most up-to-date information on relevant PBS-subsidised items, and their conditions for prescribing, see the current list in the fact sheet at www.pbs.gov.au.

New listings include antimicrobial drugs for fungal and yeast infections, otitis media and whipworm. Vitamin supplements have also been added.

The items in Table 1 are available as 'Authority PBS prescriptions'. For more information about PBS access by Aboriginal and Torres Strait Islander people, send an email to pbs-indigenous@health.gov.au

For changes to this list and other listings, readers can subscribe to news alerts from the PBS at www.pbs.gov.au/html/healthpro/ subscription/manage

\section{Table 1}

\section{PBS listings as at 1 July 2008}

Treatment of a fungal or a yeast infection

1. Bifonazole cream $(1 \%) *$

2. Clotrimazole lotion $(1 \%) *$

3. Ketoconazole cream $(2 \%)$ and shampoo $(1 \%, 2 \%)$ *

4. Miconazole nitrate (2\%) as cream, powder, lotion and tincture *

5. Nystatin cream (100 000 units per $\mathrm{g})$ *

6. Terbinafine cream $(1 \%) *$

Prophylaxis of thiamine deficiency

7. Thiamine tablet $(100 \mathrm{mg})$ *

Treatment of whipworm infestation

8. Albendazole tablet $(200 \mathrm{mg})$ *

Treatment of chronic suppurative otitis media

9. Ciprofloxacin ear drops $(0.3 \%)$

Treatment of a dermatophyte infection where topical treatment has failed

10. Terbinafine tablet $(250 \mathrm{mg})$

* streamlined authority listing 